\title{
The effect of ECS on extinction*
}

\author{
A. GRANT YOUNG and C. A. COSTELLOE \\ Louisiana State University, Baton Rouge, La. 70803
}

Sixty naive male albino rats were trained to leverpress for sucrose on either a continuous reinforcement schedule (CRF), fixed ratio (FR), or variable ratio (VR). Following acquisition, half of $\mathrm{Ss}$ in each group experienced ECS, while the other half experienced no ECS. Results of an extinction test $24 \mathrm{~h}$ after treatment showed that ECS produced a significantly increased rate of responding for CRF-trained Ss, and a nonsignificant increased rate of responding for $\mathrm{Ss}$ trained on ratio schedules.

The apparent retrograde amnesia (RA) produced by electroconvulsive shock (ECS) is typically explained in terms of a memory consolidation hypothesis (McGaugh, 1966). This hypothesis supposes that time is required, following sensory input, for the memory trace to become permanently fixed. The fixation presumably occurs through a physiological consolidation process, and if this process is interrupted by head trauma, such as ECS, the memory trace is lost and does not become fixated.

Recently, a number of studies have questioned the ability of a memory consolidation hypothesis to account for the effects of ECS. For example, Young \& Day (1971) and Young \& Galluscio (1971) have shown that, when Ss are trained on a partial reinforcement schedule (PR) and then experience footshock followed by ECS, they are not different in extinction tests from similarly treated Ss that have been trained on a continuous reinforcement schedule (CRF). The administration of ECS, then, seems to eliminate the partial reinforcement effect (PRE)-the greatly increased resistance to extinction shown by PR-trained Ss-and it does not seem that a memory consolidation hypothesis would predict this effect. In addition, other studies have produced evidence of recovery from ECS-induced RA following a "reminder shock" (Lewis, 1969). For example, Young \& Fuselier (1973) trained rats to leverpress on either CRF or PR schedules. After training, $\mathrm{S}$ experienced either footshock plus ECS or ECS only. Four hours after the treatment, half of Ss in each group received a "reminder shock." The results of an extinction test $24 \mathrm{~h}$ later showed that the "reminder shock" produced at least partial recovery from ECS-induced RA. Additionally, ECS eliminated the PRE, and the PRE was not reinstated by the "reminder shock." Again it does not seem that a memory consolidation hypothesis would predict this result.

Why ECS should eliminate the PRE is not clear. Young \& Day (1971) suggest that perhaps ECS produces

*This research was supported in part by a grant from the University Council on Research, LSU, to the first author. a type of disininibition which results in an inflated rate of responding, or a perseveration of responding in extinction.

Although this interpretation is tenable, it is not clear whether the PRE is lost through a reduction in responding in extinction for PR-trained Ss or through an increase in responding in extinction for CRF-trained Ss. Most previous studies have confounded footshock and ECS, and the present experiment was designed to determine, without the confounding effects of footshock, which of the above two possibilities is most probable.

\section{METHOD \\ Subjects}

The Ss were 60 naive male albino rats, $175-200 \mathrm{~g}$ in weight at the start of the experiment.

\section{Apparatus}

The apparatus consisted of two identical Lehigh Valley operant chambers, each enclosed in a sound-insulated ventilated cubicle. Each operant chamber had a grid floor, and fitted on the end wall was a retractable lever and a liquid dipper, which dispensed $.01 \mathrm{ml}$ of $40 \%$ sucrose solution, used as reinforcement. All E-controlled events were operated by electronic programming equipment.

\section{Procedure}

The Ss were randomly selected from the LSU colony and placed in individual cages on ad lib food and water for 4 days, after which they were placed on a food deprivation schedule of $10 \mathrm{~g}$ Purina Chow every $24 \mathrm{~h}$. Water was available in the cages at all times, and Ss were fed approximately $10 \mathrm{~min}$ after each experimental session.

From Days 5-9, Ss were handled in pairs for 5 min each day, and from Days 10-13 Ss were given magazine training on a VI 30-sec schedule. Experimental periods consisted of 20 presentations of the dipper and continued for 4 days.

On Day 14, all Ss were trained to leverpress and were allowed to make 50 reinforced responses. On the following day, all Ss were allowed to make 100 reinforced responses. On Day 16, Ss were randomly divided into three groups (CR, FR, and VR) and began acquisition training. For the $\mathrm{FR}$ group, acquisition was under an FR 2 schedule for the first 5 days and under an FR 3 schedule for the next 5 days. For the VR group, acquisition was under a VR 2 schedule throughout, and for the CR group, acquisition was under CRF throughout. All Ss were given 100 leverpresses daily for 10 days. A discrete trial procedure was used and the lever, which required $4 \mathrm{sec}$ to retract and extend fully, was inoperative during retraction.

On the day following completion of acquisition, each group was subdivided randomly, resulting in the following six groups $(\mathrm{N}=10)$ :

Groups CR(ECS), FR(ECS), and VR(ECS)-On treatment day, Ss in these three groups were fitted with a harness. Fine wire from an ECS source, which entered the operant chamber from the top, was connected to the harness, and from the harness to microalligator clip electrodes at tached to $S$ 's ears. The harness permitted complete freedom of movement to all parts of the operant chamber. The first leverpress produced a $50-\mathrm{mA}$ 5(10)-msec ECS, delivered through the earclip electrodes, and $\mathrm{S}$ was then removed to his home cage.

Groups $C R(00)$, F $R(00)$, and VR(00)-On treatment day, Ss 
Table 1

Mean Number of Leverpresses in Extinction

\begin{tabular}{cccc}
\hline Group & Total & Group & Total \\
\hline CR (OO) & 38.7 & CR (ECS) & 60.0 \\
FR (OO) & 60.1 & FR (ECS) & 65.1 \\
VR (OO) & 71.2 & VR (ECS) & 73.8 \\
\hline
\end{tabular}

in these three groups received treatment identical to that of the three ECS groups except that a leverpress did not produce ECS.

All Ss were given a 10 -min extinction test $24 \mathrm{~h}$ after treatment, and during extinction, stimulus conditions were the same as during acquisition except that the dipper was inoperative.

\section{RESULTS AND DISCUSSION}

The total number of responses made by each $\mathrm{S}$ in extinction was recorded and results showed that more responses were made by Group VR(ECS), followed in order by Groups VR(00), FR(ECS), FR(00), CR(ECS), and $\mathrm{CR}(00)$. These data were subjected to an analysis of variance which showed that both main effects of schedule and treatment were significant beyond the .01 level. The Schedule by Treatment interaction was significant beyond the .05 level, and these data were therefore subjected to an analysis of variance for simple effects. Results showed that the effect of ECS was significant beyond the .01 level for the CR groups, but was not significant at the .05 level for the FR and VR groups. Results also showed that the effect of schedule was significant beyond the .01 level for the no-treatment (00) groups, but was not significant at the .05 level for the ECS groups. Group comparisons $(t)$ showed that the comparisons $\mathrm{CR}(00)$ vs $\mathrm{FR}(00)$ and $\mathrm{CR}(00)$ vs $\mathrm{VR}(00)$ were significant beyond the .01 level, and the comparison $\mathrm{FR}(00)$ vs VR(00) was not significant at the .05 level. The mean number of leverpresses in extinction for all groups is shown in Table 1.

Acquisition response rates for the last 2 days of acquisition were recorded, and comparisons showed no significant difference within CR-, FR-, or VR-trained groups; however, the FR- and VR-trained groups, not significantly different from each other, were significantly slower than the CR-trained groups due to the discrete trial procedure ( $p<.01$, Mann Whitney $U$ ).

The finding that the FR(00) and VR(00) groups made significantly more responses in extinction than did the $\mathrm{CR}(00)$ group is the usual PRE, and was completely expected. Also the finding that ECS eliminated the PRE is consistent with earlier findings. The critical finding in this study is that ECS eliminated the PRE not through a reduction in responding for the PR-trained Ss, but through an increase in responding for the CR-trained Ss. Examination of Table 1 shows that the effect of ECS was to increase the number of responses in extinction for all groups; however, the increase was not significant for the PR-trained Ss. This finding tends to support the idea (Young \& Day, 1971) that ECS tends to produce an inflated rate of responding in extinction, perhaps through disinhibition. Presumably, ECS would affect PR-trained and CR-trained $\mathrm{Ss}$ in the same manner; however, it may be that a significant increase in responding is not obtained for PR-trained Ss due to a "ceiling" effect, i.e., an already high resistance to extinction due to the PR training schedule. The effect of increased responding on the part of CR-trained Ss, operating well below any ceiling effect, would be to decrease the difference between CR-trained and PR-trained Ss, thus eliminating the PRE. If the net effect of ECS is simply an inflated rate of responding, then any comparison between groups which experience aversive stimulation plus ECS and those which experience aversive stimulation only would make it appear that ECS had produced amnesia for the aversive stimulation, perhaps through a failure of the memory trace for aversive stimulation to become permanently fixated.

These findings suggest that although ECS appears to be an amnesic agent, the actual effect may be that of an increased activity level on the part of the organism, which increased activity is channeled into the response that the organism has learned to make in that stimulus situation.

\section{REFERENCES}

Lewis, D. J. Sources of experimental amnesia. Psychological Review, 1969, 76, 461-472.

McGaugh, J. L. Time-dependent processes in memory storage. Science, 1966, 153,1351-1358.

Young, A. G., \& Day, H. D. Effect of ECS on one-trial learning and on the partial reinforcement effect. Psychonomic Science, 1971, 24, 99-100.

Young, A. G., \& Galluscio, E. H. Recovery from ECS-produced amnesia. Psychonomic Science, 1971, 22, 149-151.

Young, A. G., \& Fuselier, G. D. ECS effects: An attempt to stimulate recovery of the PRE. Bulletin of the Psychonomic Society, 1973, 1, 322-324.

(Received for publication November 5, 1973.) 